\title{
FIRST TIME TRAUMATIC ANTERIOR SHOULDER DISLOCATION: WILL IT ALWAYS RESULT IN RECURRENT SHOULDER DISLOCATION IN ALL PATIENTS?
}

\footnotetext{
1. MBBS, FCPS (Ortho) Assistant Professor Orthopedics \& Traumatology Division Lady Reading Hospital (LRH) Peshawar, KPK, Pakistan.

2. $\mathrm{MD}, \mathrm{PhD}$

Professor \& Head Orthopedics \& Traumatology Division Lady Reading Hospital (LRH) Peshawar, KPK, Pakistan

3. MBBS, FCPS (Ortho)

Assistant Professor Orthopedics \&

Traumatology Division Lady Reading Hospital (LRH)

Peshawar, KPK, Pakistan.

Correspondence Address:

Dr. Naeemullah

Department of Orthopedics \&

Traumatology Division

Lady Reading Hospital (LRH)

Peshawar, KPK, Pakistan.

naeem117@live.com

Article received on:

06/02/2019

Accepted for publication:

$29 / 07 / 2019$
}

Faaiz Ali Shah ${ }^{1}$, Mian Amjad $\mathrm{Ali}^{2}$, Naeemullah ${ }^{3}$

ABSTRACT... Objectives: To determine the frequency of recurrent shoulder dislocation after first time traumatic anterior shoulder dislocation treated non operatively. Study Design: Prospective observational cohort study. Setting: Department of Orthopedics and Traumatology Lady Reading Hospital Peshawar. Period: 25 th May 2011 to $25^{\text {th }}$ December 2018. Material \& Methods: Patients of all ages and both gender with first time traumatic anterior shoulder dislocation meeting the inclusion criteria were included in the study. In the included subjects shoulder joint was relocated under general anesthesia and immobilized in a poly sling for four weeks followed by supervised physiotherapy and rehabilitation program without any surgical stabilization of the shoulder joint. All these patients were instructed for follow up at monthly interval or before if recurrence occurred. Results: A total of 52 patients with mean age $35 \pm 9.4$ years (range 16-55 years) were enrolled in our study. Male patients were 43(82.6\%) while female patients were $9(17.3 \%)$. Right sided dislocation was noted in $38(73 \%)$ and left in $14(26.9 \%)$. Recurrent shoulder dislocation was reported in 32(61.5\%) patients during a minimal follow up period of three years. Most $(46.8 \%, n=15)$ of the patients with recurrent shoulder dislocation were 30 years of age or below. Conclusion: First time traumatic anterior shoulder dislocation treated non operatively not always result in recurrent shoulder dislocation in all patients. However a large number of patients and particularly younger patients suffered recurrence.

Key words: Bankart Lesion, Hill Sach Lesion, Hippocrates's Technique, Shoulder Dislocation.

Article Citation: Shah FA, Ali MA, Naeemullah. First time traumatic anterior shoulder dislocation: will it always result in recurrent shoulder dislocation in all patients. Professional Med J 2020; 27(4):695-699.

DOI: 10.29309/TPMJ/2020.27.04.3227

\section{INTRODUCTION}

The incidence of shoulder dislocation in general population is $1.7 \%$ with more than $90 \%$ dislocations are anterior dislocations and are due to trauma..$^{1-3}$ The treatment of acute primary shoulder dislocation is immediate relocation of the joint and immobilization followed by rehabilitation of the shoulder joint. ${ }^{4}$ Although the optimal position of shoulder immobilization and the duration of immobilization after reduction of a dislocated shoulder joint is still controversial, the age of the patient at the time of initial dislocation is the most important factor for recurrence. ${ }^{1,5}$ The rate of recurrent shoulder dislocation after initial episode of primary traumatic dislocation treated conservatively is $65 \%$ to $97 \%$ in literature with patients under 30 years of age are at a greater risk for recurrence. ${ }^{5,6}$ Recurrent shoulder dislocation is responsible for pathological lesions in the capsule, labrum and humeral head. ${ }^{7}$ Some researchers, ${ }^{5,8,9}$ therefore recommend surgical stabilization in young professional athletes after first episode of traumatic anterior shoulder dislocation while others ${ }^{10}$ oppose it. The risk factors for recurrent shoulder dislocation include younger age of the patient ${ }^{11}$, hypermobility ${ }^{12}$, contact sports $^{13}$ and occupations involving overhead activity. ${ }^{10}$

The objective of our study was to determine the frequency of recurrent shoulder dislocation after first time traumatic anterior shoulder dislocation treated non operatively. The results of our study will help us to formulate standard treatment guidelines for traumatic anterior shoulder dislocation in our department to minimize 
recurrence and complications.

\section{MATERIAL \& METHODS}

This study was conducted in Department of Orthopedics and Traumatology Lady Reading Hospital Peshawar Pakistan from 25 ${ }^{\text {th }}$ May 2011 to $25^{\text {th }}$ December 2018.

We included patients of all ages and both gender with first time traumatic anterior shoulder dislocation sustained within a week. Atraumatic shoulder dislocation, epileptic patients posterior shoulder dislocation, multi directional instability, dislocation with fractures of the proximal humerus, previous shoulder surgery and patients with neurovascular compromise were excluded from the study.

The study was approved by the Institutional Review Board of the hospital. Informed written consent was taken from all participants of the study. X-ray shoulder joint anterio posterior and axillary view was taken. In the included subjects complete history and physical examination was done. Under general anaesthesia the shoulder joint was relocated by Hippocrates's technique ${ }^{14}$ in the operation theatre. The shoulder joint was immobilized in a poly sling for 4 weeks. Check $\mathrm{x}$-ray was done after the patient recovered from anaesthesia. The patient was discharged home with the instruction to attend supervised physiotherapy and rehabilitation programme at physiotherapy department of our hospital. Follow up of these patients were done at monthly interval or before if recurrence occurred. Cell number and emails of the patients were utilized to ensure regular follow up. Minimal follow up period was three years after initial dislocation. The second episode of dislocation or recurrence when reported was managed and rehabilitated in the same way.

Magnetic Resonance Imaging (MRI) of the shoulder joint was taken after second episode of dislocation. Patients of recurrent shoulder dislocations (after second episode of redislocation) were offered open surgery in our department if they were willing or referred to other centers for arthroscopic surgery. Statistical analysis was done by using SPSS version 21 . Categorical variables like side of dislocation and gender was represented as frequency and percentage while mean $\pm S D$ was calculated for numerical variables like age and episodes of dislocations. Data presented in graph where necessary.

\section{RESULTS}

Our study included 52 patients with mean age $35 \pm 9.4$ years (range 16-55 years). Male patients were $43(82.6 \%)$ while female patients were $9(17.3 \%)$. The mechanism of shoulder dislocation was road traffic accidents in $28(53.8 \%)$, fall in $15(28.8 \%)$, sports injury in $6(11.5 \%)$ and physical assault in 3(5.7\%). Right sided dislocation was noted in $38(73 \%)$ and left in 14(26.9\%). Recurrent shoulder dislocation was reported in 32(61.5\%) patients. All the patients were male and majority had right sided dislocation $(81.2 \%, n=26)$. Most $(46.8 \%, n=15)$ of the patients with recurrent shoulder dislocation were of 30 years and below as shown in graph I. Road traffic trauma was the cause of initial first time dislocation in $26(81.2 \%)$ patients followed by sports $(15.6 \%, n=5)$ and fall $(3.1 \%, n=1)$. Majority $(68.7 \%, n=22)$ of the patients had second episode of dislocation at 10 to 12 weeks after the initial dislocation usually with minor trauma or activity.

A small portion (31.2\%, $n=10$ ) had second episode after 12 weeks. Magnetic Resonance Imaging (MRI) of 22(68.7\%) patients after the second episode of dislocation showed HillSachs lesions in 11(34.3\%), Bankart lesions in $5(15.6 \%)$ and no pathology in $6(18.7 \%)$ patients. Other patients $(31.2 \%, n=10)$ could not do MRI. Patients younger than 30 years had a shorter interval (3-5 weeks) in between dislocation and a higher frequency of dislocations (6 to 10) per year. Majority $(56.2 \%, n=18)$ of the patients had 4 to 7 episodes of shoulder dislocation per year while $14(43.7 \%)$ patients had 2 to 3 episodes. No fracture or neurovascular compromise was reported post reduction in any of our patients. During the follow up period some of the patients $(15.6 \%, n=5)$ with recurrent shoulder dislocations were operated in our department (Boy techeve II procedure) while others $(21.8 \%, n=7)$ were 
operated in other hospitals. No patient was lost to follow up in our study.

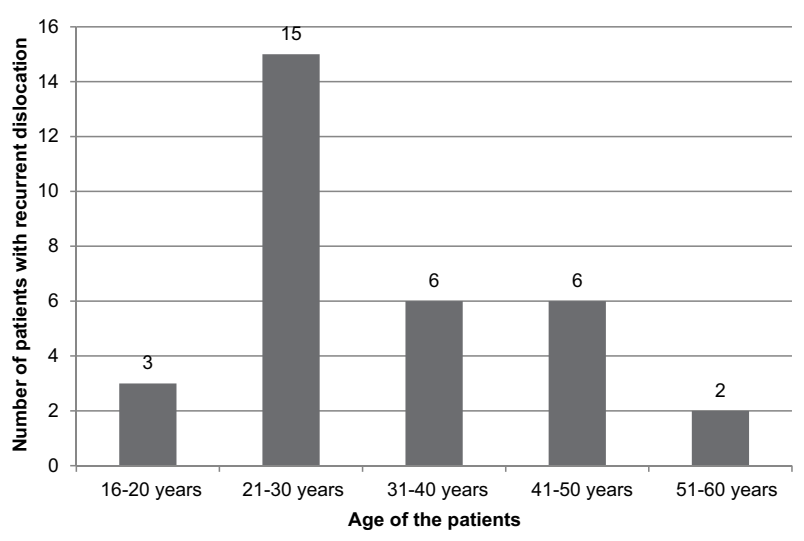

Figure-1. Age wise distribution of patients with recurrent shoulder dislocation.

\section{DISCUSSION}

Shoulder joint is one of the most commonly dislocated joint. ${ }^{15}$ The frequency of recurrent shoulder dislocation after the initial episode of traumatic dislocation managed non operatively is highest in younger patients. The re dislocation in $87 \%$ patients were reported within the first two years after initial dislocation. ${ }^{13,16}$ We reported recurrent shoulder dislocation in $61.5 \%$ of our patients within of 3 years after initial dislocation. In literature variable frequency of re dislocations have been reported. Postacchini ${ }^{17}$ reported $92 \%$ recurrence rate after primary traumatic dislocations. Sachs ${ }^{10}$ noted a recurrence rate of $33 \%$ in his 131 patients followed for four years. Hoyelius $^{18-20}$ did three excellent studies on recurrent shoulder dislocation. He documented $49 \%$ recurrence in 257 patients at the end of 10 years follow up while at 25 years follow up the recurrence rate was $72 \%$ in patients of less than 22 years at initial dislocation and $27 \%$ in patients of over 30 years. He also noted that half of the patients with first time primary dislocation had age ranges between 15 to 29 years.

In our study most $(46.8 \%, \mathrm{n}=15)$ of the patients with recurrent shoulder dislocation were 30 years of age or below. Chalidis and Sachinis ${ }^{21}$ reported $88.9 \%$ recurrence rate in 14 to 20 years age group, $70 \%$ in 21 to 30 years age and $30 \%$ to $40 \%$ recurrence in older patients especially in women. But in our study all the patients were male.
Similarly another ${ }^{22}$ study reported a recurrence rate of $64 \%$ in patients of less than 20 years of age and $6 \%$ recurrence in patients 40

years old. In our study we had not noted any patient with recurrent shoulder dislocation who was older than 60 years while Rapariz ${ }^{23}$ noted a recurrence rate of $31 \%$ in patients who were more than 60 years old. Kralinger and Golser ${ }^{11}$ observed that physical therapy and immobilization did not reduce the risk of recurrence. The only factor associated with recurrence was age particularly between 21 and 30 years and these researchers are of the opinion that younger patients with sports profession should have surgery to avoid recurrence.

Due to the higher rate of recurrence after conservative treatment of shoulder dislocation Jakobsen $^{3}$ did a randomized control trial on 76 patients age 15 to 39 years old with surgery (n $=37)$ and non-operative treatment $(n=39)$. After a minimum of 2 years follow-up majority (56\%) of the patients had recurrence recurrent shoulder dislocation after non operative treatment while only $3 \%$ suffered recurrence after surgery $(P<$ $.005)$.

In our study we found that male gender, right dominance, younger age and high energy initial trauma were the four possible risk factors for recurrent dislocation. However, small sample size and short follow up period are the limitations of our study. We recommend well designed randomized control trials with larger sample size and longer follow up period on this topic to confirm our results.

\section{CONCLUSION}

First time traumatic anterior shoulder dislocation treated non operatively not always result in recurrent shoulder dislocation in all the patients. However a large number of patients and particularly younger patients suffered recurrence. Controllable risk factors for recurrence must be identified and prevented. We recommend operatively stabilization rather than conservative treatment after first time traumatic anterior shoulder dislocation for younger patients, dominant side dislocation, sports men and 
occupations involving overhead activity.

Copyright@ 29 July, 2019.

\section{REFERENCES}

1. Rosa JR, Checchia CS, Miyazaki AN. Traumatic anterior instability of the shoulder. Rev Bras Orthop 2017; 52(5):513-520.

2. Maffulli N, Longo UG, Gougoulias N, Loppini M, Denaro V. Long-term health outcomes of youth sports injuries. Br J Sports Med 2010; 44(1):21-25.

3. Romeo A.A., Cohen B.S., Carreira D.S. Traumatic anterior shoulder instability. Orthop Clin North Am 2001; 32(3):399-409.

4. Jakobsen BW, Johannsen HV, Suder P, Sojbjerg JO. Primary repair versus conservative treatment of first-time traumatic anterior dislocation of the shoulder: A randomized study with 10-year followup. Arthroscopy 2007; 23(2):118-123.

5. Davy A, Drew S. Management of shoulder dislocation: Are we doing enough to reduce the risk of recurrence? Injury Int J Care Injured 2002; 33:775-779.

6. Bottoni CR, Wilckens JH, De Berardino TM, D'Alleyrand JC, Rooney RC, Harpstrite JK, et al. A prospective, randomized evaluation of arthroscopic stabilization versus non operative treatment in patients with acute, traumatic, first-time shoulder dislocations. Am J Sports Med 2002; 30:576-80.

7. Bishop J.A., Crall T.S., Kocher M.S. Operative versus non operative treatment after primary traumatic anterior glen humeral dislocation: Expected-value decision analysis. J Shoulder Elbow Surg 2011; 20(7):1087-1094.

8. Boone JL, Arciero RA. First-time anterior shoulder dislocations: Has the standard changed? Br J Sports Med 2010; 44:355-60.

9. Kirkley A, Werstine R, Ratjek A, Griffin S. Prospective randomized clinical trial comparing the effectiveness of immediate arthroscopic stabilization versus immobilization and rehabilitation in first traumatic anterior dislocations of the shoulder: Long-term evaluation. Arthroscopy 2005; 21:55-63.

10. Sachs RA, Lin D, Stone ML, Paxton E, Kuney M. Can the need for future surgery for acute traumatic anterior shoulder dislocation be predicted? J Bone Joint Surg Am 2007; 89:1665-1674.

11. Kralinger FS, Golser K, Wischatta R, Wambacher M, Sperner G. Predicting recurrence after primary anterior shoulder dislocation. Am J Sports Med 2002; 30:116-120.
12. Cheng SC, Sivardeen ZA, Wallace WA, Buchanan D, Hulse D, Fairbaim KJ et al. Shoulder instability in professional rugby players: The significance of shoulder laxity. Clin J Sports Med 2012; 22:397-402.

13. Robinson CM, Howes J, Murdoch H, Will E , Graham C. Functional outcome and risk of recurrent instability after primary traumatic anterior shoulder dislocation in young patients. J Bone Joint Surg Am 2006; 88:232636.

14. McRae R, Esser M. Practical fracture treatment. 4th edn. London: Churchill Livingstone, 2004; 25-30.

15. Chen HC, Phan DV, Yu L, Lee YH, Chan CL, Chou P et al. Epidemiological survey of orthopedic joint dislocations based on nationwide insurance data in Taiwan, 2000-2005. BMC Musculoskelet Disord 2011; 12:253.

16. Rowe CR. Prognosis in dislocations of the shoulder. J Bone Joint Surg Am.1956; 38:957-77.

17. Postacchini F, Gumina S, Cinotti G. Anterior shoulder dislocation in adolescents. J Shoulder Elbow Surg 2000; 9:470-4.

18. Hovelius L, Augustini BG, Fredin H, Johansson O, Norlin R., Thorling J. Primary anterior dislocation of the shoulder in young patients. A ten-year prospective study. J Bone Joint Surg Am-1996; 78(11):1677-1684.

19. Hovelius L, Olofsson A, Sandstrom B, Augustini BG, Krantz L, Fredin $\mathrm{H}$. Non operative treatment of primary anterior shoulder dislocation in patients forty years of age and younger. A prospective twenty-five-year follow-up. J Bone Joint Surg Am. 2008; 90(5):945-952.

20. Hovelius L, Saeboe M. Neer Award 2008: Arthropathy after primary anterior shoulder dislocation-223 shoulders prospectively followed up for twenty-five years. J Shoulder Elbow Surg 2009; 18(3):339-347.

21. Chalidis B, Sachinis N, Dimitriou C, Papadopoulos P, Samoladas E Pournaras J. Has the management of shoulder dislocation changed over time? Int Orthop 2007; 31 (3): 385-389.

22. Te-Sala RL, Wijffels JM, Brand R, Marti RK. The prognosis following acute primary Glen humeral dislocation. J Bone Joint Surg Br 2004; 86(1):58-64.

23. Rapariz JM, Martin SM, Bezares AP, Klein JO. Shoulder dislocation in patients older than 60 years of age. Int J Shoulder Surg 2010; 4(4): 88-92. 


\section{AUTHORSHIP AND CONTRIBUTION DECLARATION}

\begin{tabular}{|c|l|l|}
\hline Sr. \# & Author(s) Full Name & \multicolumn{1}{|c|}{ Contribution to the paper } \\
\hline 1 & Faaiz Ali Shah & $\begin{array}{l}\text { Conception and design, Acquisition } \\
\text { of data, Analysis and interpretation } \\
\text { of data. }\end{array}$ \\
\hline 2 & Mian Amjad Ali & $\begin{array}{l}\text { Final approval of the version to be } \\
\text { published. } \\
\text { Drafting the manuscript, Revising } \\
\text { it critically for important intellectual } \\
\text { content. }\end{array}$ \\
\hline
\end{tabular}

